\title{
Mothers beliefs and obstacles as limitations in promoting exclusive breastfeeding among working class mothers attending infant welfare clinic at university of Nigeria teaching hospital (UNTH), Enugu State
}

\author{
Okwy-Nweke C. P. ${ }^{1}$, Anyanwu J. O. ${ }^{2}$, Maduforo A. N. ${ }^{3}$ \\ ${ }^{1}$ Department of Nutrition and Dietetics, University of Nigeria Teaching Hospital Ituku-Ozalla, Enugu State, Nigeria \\ ${ }^{2}$ Department of Nutrition and Dietetics, Air Force Base Hospital Airport Road Abuja, Nigeria \\ ${ }^{3}$ Department of Nutrition and Dietetics Research, PMAN International Health Services, Abuja FCT, Nigeria
}

\section{Email address:}

okwynwekec@gmail.com(Okwy-Nweke C. P.), anyanwujaneonachi@yahoo.com (Anyanwu J. O.), preciousman179@yahoo.com (Maduforo A. N.)

\section{To cite this article:}

Okwy-Nweke C. P., Anyanwu J. O., Maduforo A. N.. Mothers Beliefs and Obstacles as Limitations in Promoting Exclusive Breastfeeding among Working Class Mothers Attending Infant Welfare Clinic at University of Nigeria Teaching Hospital (UNTH), Enugu State. Clinical Medicine Research. Vol. 3, No. 4, 2014, pp. 105-111. doi: 10.11648/j.cmr.20140304.15

\begin{abstract}
Objective: The research was designed to ascertain information on the mothers' beliefs and obstacles as limitations in promoting exclusive breastfeeding among the working class mothers aimed to: (1) to determine the rate of promotion of the awareness on the benefits of exclusive breastfeeding, (2) to determine the obstacles or barriers to the practice of exclusive breastfeeding, (3) to determine the percentage level of working class who practice exclusive breastfeeding, (4) to assess the nutritional knowledge and beliefs of working class mothers about exclusive breastfeeding and (5) to find out the level to which the practice of exclusive breast feeding influences the working class. Methodology: This survey study was carried out on 60 respondents which compromised of registered working class mothers attending the Infant Welfare Clinic at the Institute of Child Health, UNTH, Enugu. Structured and validated questionnaire were used to obtain information from the subjects on their socio-economic background, baby's information, promotion of exclusive breastfeeding and obstacles to exclusive breastfeeding. Data obtained from the subjects were analyzed using SPSS version 16 to determine their frequency and percentages. Result: Result showed that $91.7 \%$ of the mothers had knowledge of exclusive breastfeeding which they individually came across at different times in their lives. A small number of the mothers $38.3 \%$ practiced exclusive breastfeeding which was found to be influenced by their level of education, antenatal clinic attendance and personal conviction. $35 \%$ of them initiated breastfeeding within 30 minutes of delivery. It was observed that majority of the mothers, $80 \%$ of them do not express their breast milk. Apparently $85 \%$ of the mothers are agreed to the numerous benefits of exclusive breastfeeding. $81.7 \%$ of the mothers are of the opinion that the presence and availability of hygienic crèche in their offices will reduce the obstacles to exclusive breast feeding. The main obstacle to exclusive breastfeeding identified was absence and unavailability of hygienic crèche in office environments, followed by breast and nipple problems, perceived milk insufficiency, pressure from family and sometimes the effect of drugs taken while breastfeeding. Conclusion: Educational programme on exclusive and optimal breastfeeding should be strengthened and mothers enlightened on its importance. Therefore more behavioural changes and communication should be made to promote, protect and support exclusive breast feeding.
\end{abstract}

Keywords: Mothers Beliefs, Obstacles, Limitations, Exclusive -Breastfeeding \& Working Class Mothers

\section{Introduction}

Adequate nutrition during infancy and early childhood is fundamental to the development of each child's full human potential. It is well recognized that the period from birth to two years of age is a "critical window" for the promotion of optimal growth, health and behavioural development. Longitudinal studies have consistently shown that this is 
the peak age for growth faltering, deficiencies of certain micronutrients, and common childhood illnesses such as diarrhoea. After a child reaches 2 years of age, it is very difficult to reverse stunting that has occurred earlier (1).

Breast milk provides complete and perfect nourishment for infants, boosting their immune system and protecting them from potential killers such as diarrhoea and pneumonia. Exclusive breastfeeding also minimizes an infant's exposure to potentially unsafe food or water, and now saves an estimated six million lives every year. But too many babies are still dying because they're not being breast fed (2).

Exclusive breastfeeding is defined as "an infant's consumption of human milk with no supplementation of any type (water, juice, nonhuman milk, and foods) except for vitamins, minerals, and medications" (3). World Health Organization guidelines for feeding and nutrition of infants and young children recommend that all infants be breastfed exclusively for the first six months of life (4).

Exclusive breastfeeding based on the World Health Organization (WHO) definition refers it to the practice of feeding the baby with only breast milk (including expressed breast milk) and allows the baby to receive vitamins, minerals or medicine. Water, breast milk substitutes plus other liquids and solid foods are excluded. Both the World Health Organization (WHO) and the American Academy of Paediatrics (AAP) recommends exclusive breast feeding for the first six months of life for healthy term infants as breast milk is the best food for optimal growth, then from six months, infants should be introduced to nutrient rich, semi-solid foods with particular attention to iron, with continued breastfeeding for up to two years and beyond (4).

To enable mothers establish and sustain exclusive breast feeding for six months, WHO and United Nations Children's Fund (UNICEF) recommend:

- Initiation of breastfeeding within the first hour of life

- Exclusive breastfeeding; that is, the infant only receives breast milk without any additional food or drink, not even water for the first six (6) months of life.

- Breast feeding on demand; that is as often as the child wants, day and night.

- $\quad$ No use of bottles, teats or pacifiers (8).

Positive effects of breastfeeding on the health of infants and mothers are observed in all settings.

Breastfeeding reduces the risk of acute infections such as diarrhoea, pneumonia, ear infection, Haemophilus influenza, meningitis and urinary tract infection (5). It also protects against chronic conditions in the future such as type I diabetes, ulcerative colitis, and Crohn's disease. Breastfeeding during infancy is associated with lower mean blood pressure and total serum cholesterol and with lower prevalence of type- 2 diabetes, overweight and obesity during adolescence and adult life (6). Breastfeeding delays the return of a woman's fertility and reduces the risks of post-partum haemorrhage, pre-menopausal breast cancer and ovarian cancer (7).Increase in initiation and duration of exclusive breastfeeding is needed to realize the health, nutritional, immunological, psychological, economical and environmental benefits of breast feeding.

While breastfeeding is a natural act, it is also a learned behavior. An extensive body of research has demonstrated that mothers and other caregivers require active support for establishing and sustaining appropriate breast feeding practices. WHO and UNICEF launched the Baby Friendly Hospital Initiative (BFHI) in 1992 to strengthen maternity practices to support breastfeeding. The foundation for the BFHI is the ten steps to successful breastfeeding described in protecting, promoting and supporting breastfeeding (8).

The WHO and AAP both stress the value of breastfeeding for mothers and children. While recognizing the superiority of exclusive breastfeeding, regulating authorities also work to minimize the risks of artificial feeding. According to a WHO report, alternatives to breast feeding include:

1. Expressed breast milk from an infant's own mother.

2. Breast milk from a healthy wet-nurse or a human milk bank.

3. A breast-milk substitute fed with a cup which is a safer method than a feeding bottle and teat.

Exclusive breast feeding for the first six months of life provides continuing protection against diarrhea and respiratory tract infection (RTI) that is more common in infants fed formula. Infant formula is a modern artificial substitute for human breast milk. Formula-fed infants develop acute disease at higher rates. Formula feeding is consistently associated with immune system disorders. It is also very costly. For the reason, some mothers who are not practicing exclusive breast feeding decide to practice predominant or mixed breast feeding. Other types of breast feeding include Tandem breast feeding, extended breast feeding and shared breast feeding (8).

In Nigeria, breast feeding is a common practice among women. However, the new life and the emergence of working class women have caused a decline in breastfeeding practice. In addition, the women who are nursing infants are faced by financial and physical challenges. They are also familiar with socio-cultural practices. The common obstacle they complain against exclusive breast feeding is that they do not have enough breast milk. But the main obstacle to exclusive breast feeding identified were maternal employment, breast and nipple problems, perceived milk insufficiency, and pressure from family and sometimes the effects of drugs taken while breast feeding (9).

The promotion of exclusive breastfeeding includes the introduction of adequate complementary feed to the infant at six months, with continued breast feeding for up to two years or more. Complementary feeding is the period when the breastfed infant receives foods in addition to breast milk. As the breast feeding continues, the mother also plans to wean the baby. Weaning is the process of introducing the infant to other foods and reducing the supply of breast milk. 
The infant is fully weaned when it no longer receives any breast milk (9).

However, for the survival and proper nutritional status of the infants, they should be fully immunized for age and their growth should be monitored as well. Other health care professionals are relevant for communicating cultural and behavioural changes which should be made to promote, protect and support exclusive breastfeeding (9).

Since the recommendation of exclusive breastfeeding by WHO and AAP, much effort are expected to have been made in the areas of promotion of exclusive breastfeeding by the working class mothers who have much contact to the outside world where they work. They have more opportunity to be educated on exclusive breastfeeding and its advantages. It is expected that the rate of exclusive breast feeding should be of increase among these group of people.

On the contrary, the rate of exclusive breastfeeding among them is still low in Nigeria (9). UNICEF (2012) reported that Nearly 8 million children died in 2010 before reaching the age of 5, largely due to pneumonia, diarrhoea and birth complications. In 2010, the infant mortality rate in Nigeria was $88 / 1000$ live births, under 5 mortality rate in Nigeria was $143 / 1000$ live births and neonatal mortality rate was $40 / 1000$ live births, $12 \%$ of infants were born with low birthweight, $38 \%$ had early initiation of breastfeeding (i.e. $\leq 1$ hour), $13 \%$ were exclusively breastfed for 6 months, $32 \%$ were breastfed at age 2 years. The percentages of under-fives (2006-2010*) suffering from: underweight moderate \& severe (23\%), severe (9\%); stunting moderate \& severe $(41 \%)$ and wasting - moderate \& severe (14\%). Vitamin A supplementation coverage rate (6-59 months) 2010 (91\%) and percentage of households consuming iodized salt (2006 - 2010) was 97\% (10)

One wonders whether or not these mothers receive adequate information and assistance on exclusive breastfeeding. Education, guidance and support of mothers are highly imperative in breast feeding promotion. However, the assumption that working class mothers know enough creates barriers to breast feeding promotions among them. The adequate implementation of the recommendation of fully informed choices of infant feeding methods should be well imbibed in these women. This work is therefore designed to evaluate the mothers' belief and obstacles as limitations in promoting exclusive breastfeeding among working class mothers.

This study is specifically aimed:

1. To determine the rate of promotion of the awareness on the benefits of exclusive breastfeeding.

2. To determine the obstacles or barriers to the practice of exclusive breastfeeding.

3. To determine the percentage level of working class who practice exclusive breastfeeding.

4. To assess the nutritional knowledge and beliefs of working class mothers about exclusive breastfeeding.
5. To find out the level to which the practice of exclusive breast feeding influences the working class.

\section{Methodology}

\subsection{Research Design}

A cross-sectional survey research design was used for the study.

\subsection{Area of Study}

The study was carried out at the infant Welfare Clinic of the Institute of Child Health University of Nigeria Teaching Hospital, Enugu, Enugu State. Enugu State is located in the South-East geopolitical zone of Nigeria. University of Nigeria Teaching Hospital (UNTH), is a pioneer teaching hospital of the Nigerian country. UNTH comprises of various wards and clinics of which the Institute of Child Health (ICH) is one of them and also known as the under-5 baby clinic.

ICH is situated at the old site of UNTH. The clinic days are Mondays, Wednesdays and Thursdays at the old site, then Thursdays also at the new site. The clinic offers the following health care services in their different units.

a The medical records unit: This unit offers bio-data of children 0-5 years attending the clinic and issuing of immunization cards.

b The Nutrition Unit: This unit handles growth monitoring and promotion, food supplementation, nutrition education/counseling and nutrition rehabilitation.

c The Health Education Unit: This unit organizes group health talk on very many topics which includes exclusive breastfeeding.

d Individual Client Counseling Unit: This unit offers counseling to feeding of infant and children, feeding options for HIV positive mothers.

Other activities carried out at Infant Welfare Clinic includes immunization of women of child bearing age against tetanus, immunization against the eight childhood killer diseases, Statistical recording/analysis, de-worming from age 6 months, training of students and research.

\subsection{Subjects and Sampling}

The study sample comprises of 60 respondents who are working class mothers, with formal and non formal education attending maternal and Infant Welfare Clinic at Institute of Child Health, University of Nigeria Teaching Hospital, Enugu.

\subsection{Instrument for Data Collection}

The main instrument used was distribution of validated questionnaire and interview. The use of questionnaire was considered appropriate because the study was a survey. The questionnaires were distributed to sixty working class mothers by hand delivery. The questionnaire was collected 
108 Okwy-Nweke C. P. et al:: Mothers Beliefs and Obstacles as Limitations in Promoting Exclusive Breastfeeding among Working Class Mothers Attending Infant Welfare Clinic at University of Nigeria Teaching Hospital (UNTH), Enugu State

on the spot to ensure high percentage return. The subjects/respondents with no formal education were interviewed directly themselves. The questionnaire was divided into the following sections: Section A: Mother's personal data, Section B: Infants Information, Section C: Promoting exclusive breastfeeding and Section D: Obstacles to exclusive breastfeeding.

\subsection{Analysis of Data}

The data collected from the administered questionnaire were coded and analyzed using Statistical package for social sciences (SPSS) version 16 to determine the frequencies and percentages.

\section{Result}

Table 1. Age of the working class mothers

\begin{tabular}{lll}
\hline Mother's Age & Frequency & Percentage \\
\hline Below 20 years & 5 & 8.3 \\
21-30 years & 34 & 56.7 \\
31-30 years & 18 & 30 \\
41 and above years & 3 & 5 \\
Total & 60 & 100 \\
\hline
\end{tabular}

Table 1 shows that $5(8.3 \%)$ of the respondents are below 20 years of age, $34(56.7 \%)$ are between the ages of $21-30$ years, $18(30 \%)$ are between $31-40$ years while $3(5 \%)$ are above 40 years.

Table 2. Educational attainment of the subjects

\begin{tabular}{lll}
\hline Educational attainment of the subjects & Frequency & Percentage \\
\hline Informal/none & 3 & 5 \\
Primary education & 5 & 8.3 \\
Secondary education & 32 & 53.4 \\
Tertiary institution & 20 & 33.3 \\
Total & 60 & 100 \\
\hline
\end{tabular}

Table 2 shows that almost all the mothers had formal education except for only 3 mothers $(5 \%)$, while those that had secondary education (32 mothers) had the highest percentage of $53.4 \% .33 .3 \%$ of the mothers had tertiary education while $8.3 \%$ of them had primary education.

Table 3. Occupation of the subjects

\begin{tabular}{lll}
\hline Occupation of the mothers & Frequency & Percentage \\
\hline Farming & 0 & 0 \\
Trading & 34 & 56.7 \\
Civil servant & 18 & 30 \\
Public servant & 8 & 13.3 \\
Total & 60 & 100 \\
\hline
\end{tabular}

Table 3 shows that none of the mothers is a farmer, majority of them $34(56.7 \%)$ are trader, $18(30 \%)$ are civil servants while only $8(13.3 \%)$ of the mothers are public servants.
Table 4. Monthly income of the working class mothers

\begin{tabular}{lll}
\hline $\begin{array}{l}\text { Monthly income of the working class } \\
\text { mothers }\end{array}$ & Frequency & Percentage \\
\hline Less than 5,000 naira & 28 & 46.6 \\
6,000-20,000 naira & 18 & 30 \\
21,000-40,000 naira & 4 & 6.7 \\
$41,000-60,000$ naira & 0 & 0 \\
61,000 naira and above & 10 & 16.7 \\
Total & 60 & 100 \\
\hline
\end{tabular}

$*$ NOTE* 1 dollar $=160$ naira

Table 4 shows that $28(46.6 \%)$ i.e a greater number of the mothers receive less than 5,000 naira as their monthly pay, $18(30 \%)$ receive between 6,000 to 20,000 naira per month, only $4(6.7 \%)$ make between $21,000-40,000$ naira monthly, none of the mothers admitted she makes between 41,000-60,000 naira, but $10(16.7 \%)$ said their monthly intake home package is between 61,000 naira and above.

Table 5. Weight of infant at birth

\begin{tabular}{lll}
\hline Weight of infant at birth & Frequency & Percentage \\
\hline $2-2.29 \mathrm{~kg}$ & 6 & 10 \\
$3-3.0 \mathrm{~kg}$ & 35 & 58.4 \\
$4 \mathrm{~kg}$ and above & 17 & 28.3 \\
No idea & 2 & 3.3 \\
Total & 60 & 100 \\
\hline
\end{tabular}

Table 5 shows that a good number of the infants (35) had a birth weight of $3-3.9 \mathrm{~kg}$ i.e $58.4 \%$ of the infants while 17 (28.3\%) had between $4 \mathrm{~kg}$ and above birth weight, $6(10 \%)$ of the infant's weight was between $2-2.9 \mathrm{~kg}$ but two mothers $3.3 \%$ said they had no idea of the weight of their infants at birth.

Table 6. Period of mother's knowledge of exclusive breastfeeding

\begin{tabular}{lll}
\hline $\begin{array}{l}\text { Period of mother's knowledge of } \\
\text { exclusive breastfeeding }\end{array}$ & Frequency & Percentage \\
\hline As a single girl & 17 & 28.4 \\
After being married & 9 & 15 \\
While pregnant & 21 & 35 \\
While lactating previous infant & 8 & 13.3 \\
No knowledge & 5 & 8.3 \\
Total & 60 & 100 \\
\hline
\end{tabular}

Table 6 shows that majority of the mothers 21 (35\%) learnt about exclusive breastfeeding while they were pregnant, followed by mothers $17(28.4 \%)$ of them who heard about it when they were still single girls, then some, $9(15 \%)$ heard after being married. $8(13.3 \%)$ claimed that they heard while lactating their previous infants but 5 $(8.3 \%)$ said they have no knowledge of exclusive breastfeeding which means $55(91.7 \%)$ of the mothers are aware of exclusive breastfeeding.

Table 7 shows $37(61.7 \%)$ out of the mothers are not practicing exclusive breastfeeding and their reasons being as follows: $3(5 \%)$ of the mothers said their breast is not enough for the infant. $4(6.7 \%)$ said their infant refused breast milk, $1(1.7 \%)$ said she was sick, $6(10 \%)$ claimed 
they don't have knowledge of exclusive breastfeeding. 9 $(15 \%)$ said their knowledge of exclusive breast feeding is inadequate, $5(8.3 \%)$ said they don't like exclusive breast feeding, $7(11.7 \%)$ said it is tedious, while $2(3.3 \%)$ of the mothers don't have any reason for not practicing exclusive breastfeeding. Therefore, only 23 mothers out of the 60 mothers are practicing exclusive breastfeeding which is only $38.8 \%$.

Table 7. Reason for not practicing exclusive breastfeeding

\begin{tabular}{lll}
\hline $\begin{array}{l}\text { Reason for not practicing exclusive } \\
\text { breastfeeding }\end{array}$ & Frequency & Percentage \\
\hline Breast milk is not enough for infant & 3 & 5 \\
Infant refused breast milk & 4 & 6.7 \\
Mother was sick & 1 & 1.7 \\
No knowledge of EBF & 6 & 10 \\
Inadequate knowledge of EBF & 9 & 15 \\
I don't like it & 5 & 8.3 \\
It is tedious & 7 & 11.7 \\
No reason & 2 & 3.3 \\
Total & 37 & 61.7 \\
\hline
\end{tabular}

Table 8. Time of breastfeeding initiation

\begin{tabular}{lll}
\hline Time of initiation & Frequency & Percentage \\
\hline Within 30 minutes if delivery & 21 & 35 \\
1-12 hours after delivery & 31 & 51.7 \\
12-24 hours after delivery & 8 & 13.3 \\
Total & 60 & 100 \\
\hline
\end{tabular}

Table 8 shows that $21(35 \%)$ of the mothers breast fed their infant within 30 minutes of delivery, 31 (51.7\%) breast fed between 1-2 hours after delivery, while 8 $(13.3 \%)$ of the mothers breast fed their infants within 12-24 hours after delivery.

Table 9. Mother's beliefs about colostrums

\begin{tabular}{lll}
\hline Mother's beliefs & Frequency & Percentage \\
\hline It is good and also part of breast milk & 7 & 11.7 \\
It is rich in vitamins and minerals & 2 & 3.3 \\
It makes infants to develop well & 4 & 6.7 \\
All of the above & 41 & 68.3 \\
None of the above & 3 & 5 \\
Infant refused it & 1 & 1.7 \\
It is a bad breast milk & 2 & 3.3 \\
Total & 60 & 100 \\
\hline
\end{tabular}

Table 9 shows that the greatest number of the mothers 41 $(68.3 \%)$ agreed that it is beneficial in many ways to give the infants colostrums. $7(11.7 \%)$ of the mothers gave because it is good and also part of breast milk. 2 (3.3\%) gave only because of richness of colostrums in vitamins and minerals, $4(6.7 \%)$ gave because it makes infant to develop well. But $3(5 \%)$ did not give because they don't believe in any of the above benefits of colostrums. One mother $(1.7 \%)$ said her baby refused it, while 2 mothers $(3.3 \%)$ believed it is bad breast milk. In a nut shell, $90 \%$ of the mothers gave colostrums while $10 \%$ did not.
Table 10. Reasons for not expressing breast milk

\begin{tabular}{lll}
\hline Mothers reasons & Frequency & Percentage \\
\hline Not knowing how to do it & 24 & 40 \\
Believing it will go bad/soar & 26 & 10 \\
Not knowing how to preserve it & 4 & 6.7 \\
It is time consuming & 7 & 11.7 \\
Am always with my infant & 5 & 8.3 \\
Because of no house help & 2 & 3.3 \\
Total & 60 & 80 \\
\hline
\end{tabular}

Table 10 shows that majority of the mothers 24 (40\%) have not heard or does not know how to express their milk. $6(10 \%)$ out of them believe it will sour or go bad, $4(6.7 \%)$ claim they don't know how to preserve it, 7 (11.7\%) are of the opinion that it is time consuming, $5(8.3 \%)$ said they are always with their infants, so there is no point expressing their breast milk, then $2(3.3 \%)$ claimed they don't have house help, maybe they might be doing it. Therefore $80 \%$ of the mothers do not express their breast milk.

Table 11. Reasons for expressing breast milk

\begin{tabular}{lll}
\hline Mothers reasons & Frequency & Percentage \\
\hline $\begin{array}{l}\text { Because she leaves infant and go to work } \\
\text { So that infant will be fed on breast milk only }\end{array}$ & 9 & 15 \\
$\begin{array}{l}\text { when she is not around } \\
\text { Total }\end{array}$ & 12 & 5 \\
\hline
\end{tabular}

Table 11 shows that out of the 60 mothers in this study, only 12 mothers (15\%) express their breast milk, 9 (75\%) do it because they leave infant and go to work, the rest of the 3 mothers $(5 \%)$ express their breast milk because they want their infant to be fed on breast milk only even when they are not around.

Table 12. Mothers responses to the benefits of exclusive breast feeding

\begin{tabular}{lll}
\hline Mothers responses & Frequency & Percentage \\
\hline It makes mother and child to be close & 7 & 11.7 \\
It promotes health and prevents diseases & 12 & 20 \\
None of the above & 5 & 8.3 \\
All of the above & 32 & 53.3 \\
No idea & 4 & 6.7 \\
Total & 60 & 100 \\
\hline
\end{tabular}

Table 12 shows that a good number of the mothers believe in the numerous benefits of exclusive breast feeding. $51(85 \%)$ of the mothers seem to believe is all for good, of which $11.7 \%$ believed it makes mother and child to be close, $20 \%$ are of the opinion that it promotes health and prevents diseases while the rest believe in the general benefits. Only $5(8.3 \%)$ of the mothers are indifferent about it, while $4(6.7 \%)$ said they have no idea.

\section{Discussion}

The outcome of the study at Infant Welfare Clinic in Institute of Child Health, University of Nigeria Teaching Hospital, Enugu, Enugu State revealed the mothers' beliefs and obstacles in the promotion of exclusive breast feeding 
(EBF) among working class mothers attending the Infant Welfare Clinic. According to the mother's responses, almost all the participants believed that exclusive is the superior infant feeding method and should be practiced for the first six months postpartum. The ages of the subjects who participated in the study was found to be mainly between 21-30 years (56.7\%) (table 1). Majority of them had formal education, except for only 3 mothers (5\%) of them (table 2). It is deduced that they also have nutrition education background from the clinic they attend, which is in line with UNICE's finding that the level of education and environment of the mothers, affects breast feeding practices.

Since EBF reduces cost and only about $16.7 \%$ of the mothers earn the highest pay of 60,000 naira and above every month (table 4), EBF therefore is the reference or normative model against all alterative feeding methods, which must be measured with regards to growth, health, development and all other short-and long-term outcomes (e.g possessing higher Intelligence Quotient).

A high percentage of the working class mothers indicated that exclusive breast feeding is beneficial i.e $85 \%$ solidly agree to the very many benefits and $31.7 \%$ among them agreed to one or two benefits of EBF (table 12). This might be as a result of programmes aimed at promoting exclusive breast feeding, resulting to increased awareness and probably an elevated rate of practice.

Surprisingly, $61.7 \%$ of the mothers are not practicing exclusive breast feeding, they are still not convinced that an infant can thrive on breast milk alone for the first 0-6 months of life (table 7) but by the end of the study many working class mothers understood the concept of exclusive breastfeeding and showed interest in practicing it.

Insufficient breast milk supply was also reported by the mothers. This was probably because of mother's inadequately food intake and improper positioning and attachment. Nwazor (1994), stated that nutritional status of mothers affects their milk output. Also a mother's attitude physical/mental state can affect the flow of breast milk. However, attitude and practice depends on the level of education, occupation, antenatal clinic attendance, environmental and personal conviction (9).

Table 13. Obstacles to exclusive breast feeding

\begin{tabular}{lllll}
\hline Supposed obstacles & Frequency of true & Percentage of true & Frequency of false & Percentage of false \\
\hline $\begin{array}{l}\text { My mother in-law will not agree that we go against } \\
\text { tradition by not giving baby water }\end{array}$ & 23 & 38.3 & 37 & 61.7 \\
Breast milk does not contain sufficient water and nutrients & 24 & 40 & 36 & 60 \\
Babies need variety of foods between 0-6 months & 10 & 16.7 & 50 & 83.3 \\
Mother should discontinue breast feeding when sick & 9 & 15 & 51 & 85 \\
$\begin{array}{l}\text { Mothers who exclusively breast feed lose their shape and } \\
\text { have flat breast }\end{array}$ & 11 & 18.3 & 49 & 81.7 \\
$\begin{array}{l}\text { EBF affects a woman's job negatively } \\
\text { It is shameful to breastfeed in the public }\end{array}$ & 70 & 33.3 & 40 & 66.7 \\
$\begin{array}{l}\text { Absence and unavailability of hygienic crèche in office } \\
\text { environment }\end{array}$ & 49 & 11.7 & 53 & 88.3 \\
$\begin{array}{l}\text { Four months maternity leave does not encourage exclusive } \\
\text { breast feeding }\end{array}$ & 22 & 81.7 & 11 & 18.3 \\
\hline
\end{tabular}

Obstacles to EBF seem to be imaginary and may arise when a mother's mind-set is not made up. It is only the absence and unavailability of hygienic crèche in office environment that got a higher percent $(81.7 \%)$ as an obstacle to EBF, the rest have been countered by the mothers opinions (table 13). Obstacles to EBF can be taken care of by combined efforts and responsibilities by individuals, the government and society. These obstacles arise because of insufficient perinatal education on EBF.

Despite efforts of different government and NonGovernmental Organization (NGOs). EBF rate is still low, traditional and cultural barriers still exist. This can be overcome by educating both parents, before and after delivery of the infant, nothing that the concept is the EBF is an infant's consumption of human milk with no supplementation of any type (no water, no juice, no non human milk, and no foods), except for vitamins and minerals and medications from 0-6 months of life.

\section{Recommendations}

The reports from this survey recognize that exclusive breast feeding (EBF) to 6 months is still infrequent. However, it also notes that there have been substantial increases over time to the promotion of EBF, especially at the location of this survey, where lactation support is available. A pre-requisite to the implementation of the recommendation is the provision of adequate social and nutritional support to lactating mothers in general. In order to remove the harmful cultural beliefs and to spread the messages of the benefits of EBF for the survival and nutritional status of the children, more behavioural changes and communication should be made to promote, protect and support EBF, thus the following recommendations:

1. Healthy infants should be placed and remain in direct skin-to-skin contact with their mothers immediately after delivery until the first feeding is 
accomplished. Delay weighing, measuring, bathing, needle sticks and eye prophylaxis until after the first feeding is completed.

2. During the early weeks of breastfeeding, mothers should be encouraged to have 8 to 12 feedings at the breast every 24 hours, offering the breast whenever the infant shows signs of hunger such as increased alertness, physical activity or mouthing.

3. Education of both parents and expanded target group to include elders and husbands, before and after delivery of the infant is an essential component of successful EBF. They are highly influential in matters regarding patterns of child feeding.

4. The expert consultation recommends EBF for 6 months, with introduction of nutritionally adequate, safe and appropriate complementary foods, rich in iron, which should be introduced gradually beginning around 6 months of age, in conjunction with continued breast feeding thereafter, for at least the first year of life and beyond for as long as it is mutually desired by mother and child.

5. The proportion of infants exclusively breastfed at 6 months can be maximized if potential problems are addressed such as

a The nutritional status of pregnant and lactating mothers.

b Micronutrient status of infants living in areas with high prevalence of deficiencies such as iron, zinc and vitamin A.

c The routine primary health care of individual infants, including assessment of growth and of clinical signs of micronutrients deficiencies.

6. Encourage the media houses to portray EBF as positive and normative.

7. Efforts should be made in private and government hospitals to help educate the few mothers who are yet to be convinced on the practice of EBF in clinics like antenatal clinics, home-visits, outreach services and in social gatherings.

8. The effect of cultural diversity on breast feeding attitudes and practices should be re cognized while appropriate measures should be taken to encourage variations that will effectively promote and support EBF in different cultures.

9. Younger generations should learn about the importance of EBF. Encourage development of formal training on EBF and lactation in medical schools, in residency and fellowship training programmes, and for practicing pediatricians.

10. Encourage employers to provide appropriate facilities and adequate time in the work place for breast feeding and or milk expressing.

11. Mothers should be taught and encouraged to express breast milk for their exclusively breastfed infants in situations where their domestic, official or social responsibilities would interfere with the success of this practice.

12. To develop and maintain effective communication and co-ordination, with other health care professionals to ensure optimal EBF education support and counseling.

13. To promote continued basic and clinical research in the field of EBF.

14. Encourage development and approval of governmental policies and legislation that are supportive of a mother's choice to breast feed.

15. Provide counsel to adoptive mothers who decide to breastfeed through induced lactation, a process requiring professional support and encouragement.

16. Support the efforts of parents and the courts to ensure continuation of EBF in separation and custody proceedings.

\section{References}

[1] Martorell R, Kettel K. L, and Schroeder D.G. (1994) Reversibility of stunting: epidemiological findings in children from developing countries. Eur J Clin Nutr;S45S57.

[2] O'Brien, J. (2010) Six million babies now saved every year through exclusive breastfeeding. www.unicef.org

[3] Gartner L.M. (2005). "Breastfeeding and the use of human milk [policy statement"]. Pediatrics 115 (2): 496-506

[4] WHO (2000) Feeding and Nutrition of infant and young children Guidelines for the WHO European Region. WHO Regional Publications, European series, no 87.

[5] Technical updates of the guidelines on Integrated Management of Childhood Illness (IMCI). Evidence and recommendations for further adaptations. Geneva, World Health Organization, 2005.

[6] Evidence on the long-term effects of breastfeeding: systematic reviews and meta-analyses. Geneva, World Health Organization, 2007.

[7] León-Cava $\mathrm{N}$ et al. Quantifying the benefits of breastfeeding: a summary of the evidence. Washington, DC, Pan American Health Organization, 2002 (http://www.paho.org/English/AD/FCH/BOB-Main.htm, accessed 26 June

[8] WHO and UNICEF (2009) Baby-friendly hospital initiative: revised, updated and expanded for integrated care. Section 2 , Strengthening and sustaining the baby-friendly hospital initiative: a course for decision makers. World Health Organization, 20 Avenue Appia, 1211 Geneva 27, Switzerland

[9] Nwazor F. O., (1994). Successful breastfeeding Onitsha: IfeLithe Print pp. 40-61

[10] United Nations Children's Fund (UNICEF) (2012) THE STATE OF THE WORLD'S CHILDREN 2012 United Nations publications www.unicef.org/sowc2012. 